Principal Investigator: Zachary E. Lowe, Purdue University, zach@clft.org, 765.494.3531

Program Office: jtrp@purdue.edu, 765.494.6508,www.purdue.edu/jtrp

Sponsor: Indiana Department of Transportation, 765.463.1521

SPR-3414

\title{
Integrated Vegetation Management (IVM) for INDOT Roadsides
}

\section{Introduction}

The Indiana Department of Transportation (INDOT) manages right-of-way vegetation on 11,000 miles of roadside. According to INDOT maintenance records, mowing is currently the main form of vegetation management on Indiana roadsides, constituting the third largest time commitment for INDOT employees. While mowing is an important vegetation management tool, it is also expensive, often promotes weeds, and only offers temporary relief from broadleaf weed and grass height concerns. Incorporation of multiple management tools as part of an integrated vegetation management (IVM) program has helped multiple state agencies develop an efficient and effective roadside vegetation program.

The first portion of this study examines the use of herbicide and mowing at six sites throughout the state of Indiana. Two mowing treatments, six herbicide treatments, and an untreated control were compared for their ability to decrease broadleaf species cover and maintain grass height. Mowing treatments included a one-cycle mowing treatment consisting of an early growing season mow (late May to early June 2011) and a two-cycle mowing treatment consisting of both an early (late May to early June 2011) and late growing

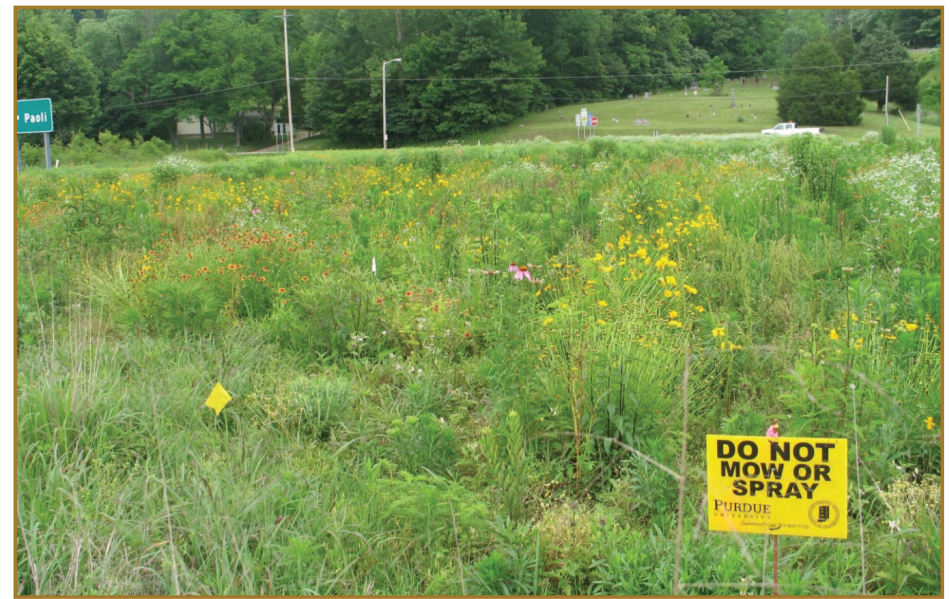

Photograph of T4 (short grass and forbs) one year after planting at the Vincennes District site. season mow (August 2011). Herbicide treatments were foliar applied in May 2011 and included tank mixes consisting of aminopyralid (Milestone $®$ ), imazapic (Plateau $®$ ), 2,4-dichlorophenoxyacetic acid (2,4-D®) metsulfuron methyl (Escort $\AA$ ), and aminocyclopyrachlor (Perspective $\AA$, Viewpoint $\AA$ and Streamline $囚)$.

For the second portion of the study, four native seed mixes (western wheatgrass, short grass, tall grass, and short grass with forbs) were evaluated for use as alternatives to traditional non-native roadside vegetation. Determination of successful planting was based on density of planted species one year after planting at six sites throughout the state of Indiana.

\section{Findings}

This study evaluated three IVM tools: herbicide, mowing, and native species. Herbicide and mowing were evaluated for management of broadleaf weeds and grass height. Native plantings were evaluated as alternatives to traditional vegetation.

\section{Herbicide Treatments}

Broadleaf cover in all six herbicide treatments was reduced rapidly and remained low for 12 months after application. Informal observations also suggest reduced broadleaf presence at 24 months. All herbicide treatments also kept grass under 15 inches for three months after application. All six herbicide treatments regulated grass height equally, therefore we saw no added grass height management benefit in treatments containing imazapic. These results may differ during years with less severe droughts. It was calculated that average herbicide application on INDOT roadsides costs $\$ 36 /$ mile and could cover 60 miles/day.

\section{Mowing Treatments}

Mowing treatments offered no decrease in broadleaf cover at any point during this study. Grass mowed early in the growing season regrew 7 inches in just two weeks, while grass mowed late in the growing season only regrew 1-3 inches in two weeks. Therefore, waiting until later in the growing 
season (after all grasses have gone to seed) would result in the longest lasting results for a mowing cycle. One cycle of mowing cost costs $\$ 64 /$ mile and can cover 18.5 miles/day, making it a slower and more costly option than any of our herbicide treatments.

\section{Native Plantings}

One year after planting, research sites averaged 1.7 native plants per square meter, covering only $6 \%$ of the planted area. However, informal visual observations two years after planting suggest that some sites may have become successful. Low cover of native species was likely due to two years of drought. We therefore suggest that native plantings be planned for non-drought years whenever possible, and that further research into planting densities and species selection during drought years be investigated. Weed competition was also a main concern, showing the importance of site preparation prior to planting. Western wheatgrass was the most successful grass species and native forbs were fairly successful at two of the sites

\section{Implementation}

An overall reduction in mowing is essential to reducing vegetation management costs. This can be done by altering current mowing cycles, including herbicide, and planting native species. The results of this study show that a selective broadleaf control herbicide, with the possible addition of growth regulators, offers a longer lasting solution to weed and height control than mowing. A cost savings of over $40 \%$ can be achieved with one application of herbicide in lieu of

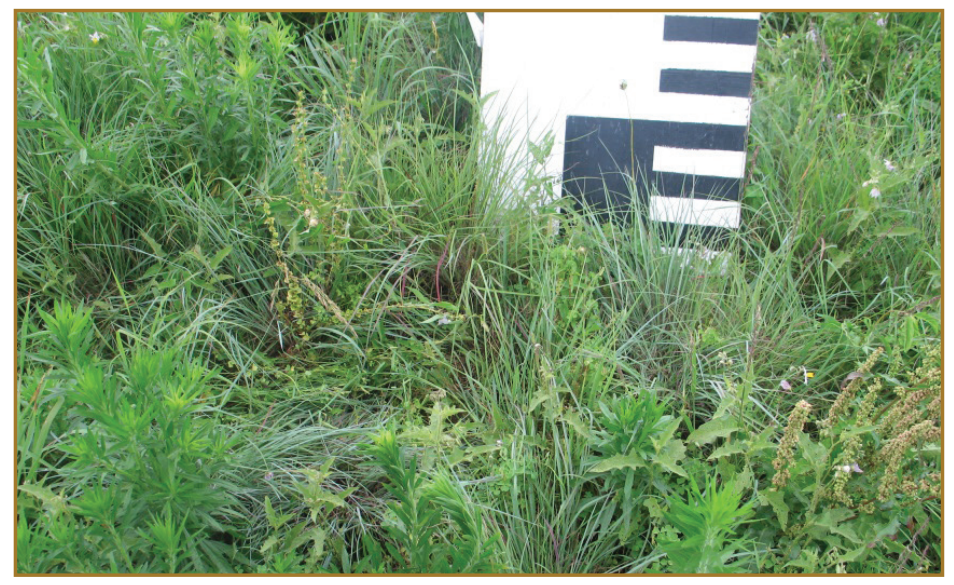

Photograph of T3 (short grass) one year after planting at the Vincennes District site. one cycle of mowing. Visual observations showed that one herbicide application reduced broadleaf weed presence not only in the year applied, but also for the two growing seasons that followed. This potential of three years of weed control on INDOT roadsides offers greater cost savings than originally thought. Planting native vegetation offers the potential for even further cost savings by eliminating multiple mowing and herbicide cycles once established.

Research findings were presented at multiple trainings for INDOT, vegetation management organizations, academic programs, and to the public. Many changes to vegetation management on INDOT roadsides have been instituted during the time frame of this project, in part due to the findings presented at these meetings. The timing of the first mowing cycle has been moved to later in the growing season, when grasses will grow less quickly after being cut. Regulations on mowing heights have also been changed in order to prevent killing turf by mowing grass too short. Also, large scale herbicide treatments are being tested, as well as an emphasis on broadleaf control.

Further reduction in mowing cycles may be achieved with native roadside plantings. INDOT has already successfully incorporated native plantings into right-of-ways as part of the Hoosier Roadside Heritage Program. The cost of management in these areas has required drastically less maintenance than the traditional roadside. Although this study resulted in only low cover of native plants the year after planting, visual observations two years after planting show that some sites may indeed be successful. Therefore, further data collection should be conducted to determine success. This study also shows a need for further research into planting during drought years, including planting rates, seed mixes, and management. Lastly, this study shows the importance of site preparation before planting, as well as the large problem that invasive species cause to roadside plantings.

\section{Recommended Citation}

Herold, J. M., Z. E. Lowe, and J. S. Dukes. Integrated Vegetation Management (IVM) for INDOT Roadsides. Publication FHWA/ IN/JTRP-2013/08. Joint Transportation Research Program, Indiana Department of Transportation and Purdue University, West Lafayette, Indiana, 2013. doi: 10.5703/1288284315210.

View the full text of this technical report here: http://dx.doi.org/10.5703/1288284315210

Published reports of the Joint Transportation Research Program are available at http://docs.lib.purdue.edu/jtrp/.
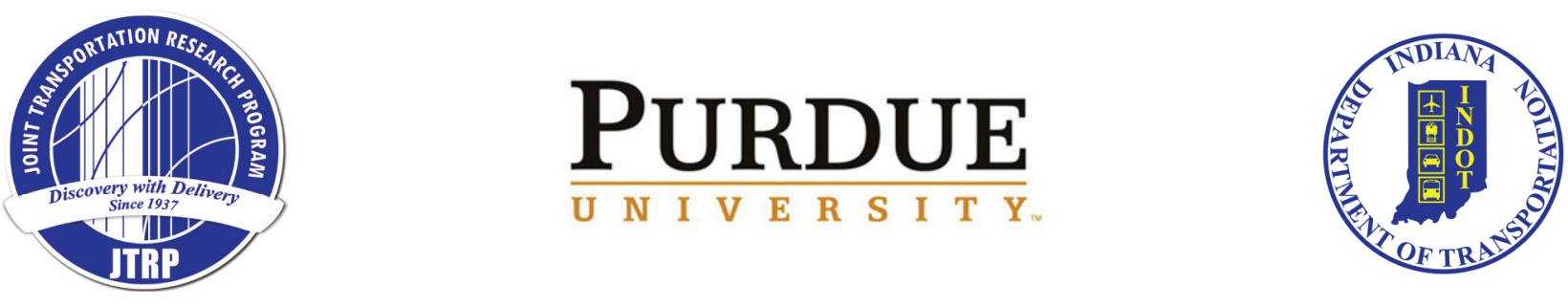